\title{
Arqueologia Histórica e a Problemática do Patrimônio: discussões acerca da preservação, turismo e educação patrimonial no Vale do Taquari - Rio Grande do Sul. \\ Neli T. Galarce Machado ${ }^{\circ}$ Sérgio Nunes Lopes"• Diego Antônio Gheno •••
}

\begin{abstract}
Resumo: As pesquisas em Arqueologia Histórica no Vale do Taquari são recentes, e buscam um melhor entendimento do cotidiano dos grupos humanos provenientes da colonização portuguesa do século XVIII e da imigração européia do século XIX. Dentre as origens destes grupos, podemos citar basicamente açorianos, alemães e italianos. Além disso, a Arqueologia Histórica é uma área de fundamental importância nas pesquisas arqueológicas e na divulgação das mesmas, pois, tem apelo à preservação do Patrimônio Histórico-Cultural e a possibilidade de, a partir de informações concretas, produzir conhecimentos capazes de corrigirem distorções construídas historicamente. Estes são alguns dos enfoques dados no presente trabalho. A interconexão com a capacidade comunicativa da educação e do turismo são alguns dos meios apresentados aqui como potenciais para a preservação do Patrimônio no Vale do Taquari. No que se refere à educação patrimonial, entretanto, alguns dados concretos são partilhados,
\end{abstract}

- Professora Doutora - Centro de Ciências Humanas e Jurídicas Centro Universitário Univates - 95900-000 - Lajeado - RS - Brasil. Email: nelitgm@terra.com.br

- Graduando em História - Bolsista de Iniciação Científica - Centro Universitário Univates - 95900-000 - Lajeado - RS - Brasil. E-mail: sergionl77@hotmail.com

-. Graduando em História - Bolsista de Iniciação Científica - Centro Universitário Univates - 95900-000 - Lajeado - RS - Brasil. E-mail: digheno@yahoo.com.br 
NELI T. G. MACHADO; SÉRGIO N. LOPES E DIEGO A. GHENO

uma vez que as pesquisas realizadas neste contexto têm obtido resultados satisfatórios.

Palavras-chave: Arqueologia Histórica, Patrimônio Cultural, Vale do Taquari.

\section{A problemática do patrimônio cultural e as possibilidades educacionais}

Antes de considerar as pertinências educacionais do Patrimônio Cultural, faz-se necessário defini-lo com base em autores que, ousadamente, justificam a necessidade da preservação como forma de promoção da cidadania em tempos de crises identitárias. Dessa forma, para a presente abordagem, considerar-se-á Patrimônio Cultural o "conjunto de todos os utensílios, hábitos, usos e costumes, crenças e forma de vida cotidiana de todos os segmentos que compuseram e compõem a sociedade." (BARRETO, 2000: 11).

No contexto local, cabe ressaltar o Patrimônio Cultural Material como âncora para elucubrações capazes de possibilitar o trânsito policrônico na formação cultural da região.

Apesar de iniciativas particulares isoladas no que se refere à preservação patrimonial no Vale do Taquari/RS, muito há que se fazer sob o ponto de vista concreto, para que a potencialidade desse patrimônio seja explorada a contento. A Arqueologia Histórica é uma disciplina que através do seu suporte metodológico pode colaborar nesse sentido. Os casarões do período da colonização portuguesa e as casas dos primeiros imigrantes do século XIX, principalmente italianos e alemães, são representações do cotidiano de cada um desses grupos que legaram, através do seu modo de vida, muitos dos fatores determinantes na configuração social atual dessa região.

Assim sendo, essas estruturas arquitetônicas, bem como o seu entorno adquirem o status de Patrimônio Histórico-Cultural. Conforme Oosterbeek (2007: 128), "incorporamos no Patrimônio Cultural todos os vestígios, materiais e imateriais, do Passado, 
sublinhando sua diversidade e pluralidade de leituras, e destacando a sua relevância para a construção de múltiplos futuros". A partir de uma perspectiva arqueológica, a análise dos objetos encontrados nas referidas estruturas arquitetônicas podem evidenciar modos de vida específicos de cada família ou comunidade. Além de enquadrarem-se na definição de patrimônio acima referida, arqueologicamente falando, essas construções recebem a definição técnica de Sítios Arqueológicos e os objetos encontrados em seu interior ou arredores são, segundo a mesma ciência, Cultura Material.

Explorar o Patrimônio Cultural sob o prisma da educação em tempos de paradigmas educacionais transdisciplinares torna-se imperativo. Mesmo restringindo as possibilidades ao componente curricular "História", não se pode prescindir de fontes de informação alternativas como forma de potencializar o entendimento dos acontecimentos regionais em relação com outros de impactos mais abrangentes.

Durante muito tempo, a supremacia do documento escrito unilateralizou as abordagens historiográficas privilegiando os grupos sociais capazes de produzirem essas informações crivadas de meandros ideológicos, cuja finalidade primeira é perpetuar a ordem social conforme conviesse à classe dominante. Num processo bem conduzido de Educação Patrimonial, esse tipo de risco diminui pela pluralidade de interpretações possíveis a cada agente observador.

Lançar mão das informações originárias do Patrimônio Cultural na educação é, de certa forma, estabelecer a conexão que falta no contexto do Vale do Taquari entre a consciência da preservação, incipiente em algumas comunidades, e as verdadeiras justificativas históricas desse ato. $O$ sucesso almejado nesses empreendimentos terá seus méritos na mesma medida em que os atores envolvidos forem capazes de problematizar adequadamente, conforme sugere Grunberg ao referir uma visita a um dos lugares de guarda e estudo do Patrimônio: 
NELI T. G. MACHADO; SÉRGIO N. LOPES E DIEGO A. GHENO

A visita que foi utilizada como motivação permitirá um desenvolvimento do aprendizado muito mais rico e proveitoso. Quem morou naquela casa, como viviam as pessoas, em que época, o que comiam, como trabalhavam e brincavam, como praticavam esportes e se divertiam, quais eram, como se curavam as doenças, de que tipo, em que acreditavam, como pensavam, de que gostavam? Como eram os ricos, que relação tinham com os pobres, existiam diferenças ou eram todos iguais? (GRUNBERG, 1999: 108).

O trânsito entre o abstrato da informação e o concreto da materialidade patrimonial pode facilitar as associações que todo o educador almeja, pois,

Ao desenvolver este trabalho, possibilita-se aos alunos aprender sobre o passado, conhecê-lo e dar-lhe valor. Referenciá-lo com o presente permitirá à criança a comparação e o desenvolvimento do seu espírito crítico, fator essencial na formação do futuro cidadão. (GRUNBERG, 1999: 108).

Restringindo a concepção de patrimônio aos monumentos arquitetônicos e arqueológicos, como forma de dinamizar essa parte específica da discussão, não se pode desvinculá-los da consciência histórica.

Nesse sentido, buscar entender o Patrimônio Cultural isolado das características individuais e coletivas é um equívoco, quando não um desrespeito à sociedade. Tanto a ciência quanto o Patrimônio Cultural têm responsabilidade social mas, principalmente, devem estar voltados à busca de melhorias de vida da população (FOGOLARI, 2005: 23).

Em última análise, a Educação Patrimonial é "um processo permanente e sistemático de trabalho educacional centrado no Patrimônio Cultural como fonte primária de conhecimento e enriquecimento individual e coletivo." (HORTA, 1999). Nessa perspectiva, os sítios já pesquisados no Vale do Taquari estão em processo de significação através do trabalho gradativo 
desempenhado junto às escolas, o que tende a gerar laços cada vez mais autênticos do ponto de vista da pluralidade de interpretações sobre a sociedade em questão.

A partir dos estudos até então desenvolvidos, cabe considerar as potencialidades turísticas tomando como exemplo situações semelhantes em outras regiões do Estado e do País. Refletir, no entanto, sobre as outras regiões só se torna válido se a proposta não for calcada no pragmatismo do transplante de modelos mercadológicos.

A partir do exposto, não sem dificuldades, historiadores, arqueólogos, arquitetos e turismólogos devem buscar os fatores comuns que os congregam em torno do Patrimônio sob pena de nem um nem outro alcançar êxito em seus empreendimentos.

Um trabalho que congregue a visão pluridisciplinar desses profissionais diminuirá a probabilidade de repetição de erros cometidos em outros contextos por motivos que vão desde emaranhados políticos até posicionamentos intransigentes oriundos de visões de intelectuais dogmáticos e do egocentrismo que permeia o fazer científico em algumas ocasiões.

As relações tempo-espaciais, possibilitadas pela história, os traços culturais específicos revelados pela cultura material e as evoluções técnicas espontâneas ou pré-determinadas emanadas da arquitetura, possibilitarão ao produto turístico ultrapassar a unilateralidade econômica, acentuando no agente dessa área a potencialidade comunicativa da preservação. Alguns autores vislumbram uma aproximação frutuosa nesse sentido:

O Turismo através do estudo da cultura pode se promover não só como atividade capitalista, que desequilibra os ambientes, e sim; sendo uma atividade também capitalista, mas que conserve e preserve os ambientes (nossos patrimônios). (VARELA, 2003).

A mesma autora pontua, de forma ainda mais incisiva, a importância do papel de cada área do conhecimento perante o Patrimônio Cultural: 
Assim temos a educação como recurso e o turismo como um produto. Mostrando desde então que a capacidade e aptidões específicas do homem não se transmitem por herança biológica, mas que se formam durante a vida, no processo de apropriação da cultura criada pelas gerações anteriores. (VARELA, 2003).

A preocupação última, tanto da educação quanto do turismo, deve ser aproximar o cidadão do que é seu por direito, o Patrimônio Cultural. Essa aproximação pode remetê-lo a conexões ilimitadas, dando-lhe autonomia para se desvencilhar dos enredos ideológicos que permeiam as relações sociais.

A partir do amadurecimento e da identificação de cada cidadão com tudo o que pode evocar sua cultura, pode-se ambicionar investimentos mais significativos. A experiência do desenvolvimento turístico em Ouro Preto/MG ilustra como no início a sociedade civil "patrocinou" a expansão das atividades turísticas credenciando-se a investimentos estatais:

Os "currais" eram fazendas que serviam, principalmente, para pernoite dos viajantes e descanso para os animais. Na ocasião, as pessoas, ficavam hospedadas normalmente na sede da fazenda, não pagando pelo pouso, e sim pela permanência dos animais no curral; fato explicado pelo lucro obtido pela venda do feno. Chamavam-se hotéis tipo estalagem, "estalações" que eram casas familiares, mas destinavam-se também a hospedar pessoas. (SILVA, 2004).

O Estado tem participação determinante no sucesso ou não dos empreendimentos tanto do ponto de vista educacional quanto do ponto de vista turístico. As políticas públicas determinam tanto a acessibilidade quanto o fomento a projetos nessa área. Todas as estratégias do profissional imbuído do trabalho com o Patrimônio, portanto, estão diretamente relacionadas à gestão do Estado, enquanto órgão oficial de "representação da vontade do povo". 
AROUEOLOGIA HISTÓRICA E A PROBLEMÁTICA DO PATRIMÔNIO...

Para Fogolari, a presença do Estado na Cultura e Gestão do Patrimônio Cultural deve ser da forma mais democrática possível, considerando a diversidade, porque, como afirma Zarankin (2002: 15) "a cultura material é carente de significados por ela mesma, e só adquire uma dimensão ativa dentro de um sistema cultural determinado". Ou seja, uma determinada situação não anula a capacidade dialética existente nos objetivos do Patrimônio Cultural (2005: 24).

Segundo Oosterbeek, o patrimônio não pode ser apropriado por Estados ou outras formas de organização social. Mesmo sendo assumido por diversos segmentos da Humanidade, para assim ter sua gestão não como meramente conservacionista, mas como articuladora do desenvolvimento, numa ótica de "sustentabilidade" (2007: 129).

Em relação à memória, à tradição e à singular vinculação do patrimônio, estes se situam numa encruzilhada que envolve tanto o papel na construção de identidades coletivas, quanto os recursos a que têm recorrido os Estados modernos na objetivação e legitimação da idéia de nação (FONSECA, 2005: 51).

No Vale do Taquari, as políticas públicas nessa área são escassas. São raros os municípios que possuem museus ou arquivos públicos sistematizados. Mesmo aqueles que dispõem de algum espaço nesse sentido, não investem o quanto poderiam. Talvez por esse motivo, uma parte significativa do Patrimônio Cultural local esteja sendo carcomida por traças em armários particulares ou nos porões insalubres das prefeituras, alheia aos profissionais competentes para o seu manuseio, capazes de estabelecer as conexões entre 0 cidadão contemporâneo e o seu passado. 


\section{Os primeiros passos de uma pesquisa científica genuninamente local}

Do ponto de vista acadêmico, alguns passos significativos já foram dados no sentido de atender a tal demanda, a partir das atividades desenvolvidas pelo Museu de Ciências Naturais do Centro Universitário UNIVATES e das pesquisas arqueológicas iniciadas concomitantemente à instituição do curso de História no referido educandário. Primeiramente, com os passos que já foram dados, aos poucos a consciência do valor cultural do patrimônio tende a se solidificar.

Verifica-se, no entanto, a necessidade do entendimento de que o Patrimônio Cultural não pertence a um indivíduo em particular, mas a toda a sociedade. Uma vez esclarecidas essas questões, as potencialidades tanto educacionais quanto turísticas se concretizarão, permitindo que as informações sejam âncoras para o conhecimento que liberta. Neste sentido, indo muito além dos muros das universidades e justificando socialmente a sua existência.

O conhecimento do passado referencia a construção do futuro de cada região, instituição ou indivíduo. Pesquisar o Patrimônio Histórico do Vale do Taquari, seja ele histórico ou pré-histórico, é uma forma de firmar o caráter comunitário do Centro Universitário UNIVATES como instituição acadêmica comprometida com as questões regionais.

O comprometimento com projetos dessa natureza, no entanto, extrapola os limites institucionais, ou pelo menos deveria extrapolá-los. No caso específico do projeto em questão, o suporte dado pela FAPERGS (Fundação de Amparo à Pesquisa do Estado do Rio Grande do Sul) foi indispensável. Além das razões institucionais anteriormente mencionadas, esse tipo de abordagem vem suprir lacunas existentes em relação ao conhecimento do passado da região, cujas condições geográficas favorecem a ocupação humana, ainda pouco estudada.

A pesquisa arqueológica é realizada em benefício da comunidade, aproximando a Instituição da mesma, inteirando-a 
numa proposta de valorização e preservação do Patrimônio Histórico e Arqueológico, pois o patrimônio "é mais que um testemunho do passado, o patrimônio é um retrato do presente, um registro de possibilidades políticas dos diversos grupos sociais, expressas na apropriação de parte da herança cultural." (Rodrigues, 1996).

Conscientes desse status que o Patrimônio possui, a comunidade tende a se apropriar dele de maneira fecunda, tanto no que se refere ao conhecimento difundido através da educação formal ou informal, como através do turismo, que pode ir além da mera exploração econômica e atuar como difusor da cultura regional. Para que se possam desenvolver trabalhos de conscientização e de valorização do Patrimônio Histórico e arqueológico, é necessário que a instituição conheça o patrimônio que existe nos municípios, a fim de estudá-lo e preservá-lo não apenas para mera contemplação, mas para aproveitá-lo como testemunhos da história que resiste aos tempos. Enquanto que a Arqueologia estuda, diretamente "a totalidade material apropriada pelas sociedades humanas, como parte de uma cultura total, material e imaterial, sem limitações de caráter cronológico." (Funari, 1988).

Estes testemunhos, que nasceram como residências, casas comerciais e acampamentos de grupos pré-históricos e horticultores indígenas, possuem valor documental, são fontes de estudo inéditas, esperando para serem exploradas, pois "a valorização econômica de regiões com monumentos arqueológicos, o desenvolvimento do turismo popular e a participação da população local nas escavações e restaurações são práticas comuns em diversos países".(Funari, 1988).

Uma vez levantados os dados acerca do patrimônio local, cabe àqueles que se encontram aí representados dinamizar as informações para que elas se tornem conhecimento. Nesse sentido, as disciplinas de Patrimônio Turístico Cultural do Curso de Turismo e as muitas disciplinas do curso de História, são os meios através dos quais este conhecimento flui. Daí, é possível se depreender que a possibilidade de apreensão não se restringe exclusivamente aos meios formais. Assim como as 
estruturas e os objetos, as pessoas cujos atos são princípio e fim desse estudo qualificam e legitimam o esforço intelectual tanto discente quanto docente. A coleta de informações e registros fotográficos efetivam-se nas saídas de campo.

A abordagem, especificamente no caso das estruturas arquitetônicas históricas, se dá a partir de uma ficha elaborada em laboratório onde se registram as principais características arquitetônicas da construção. Além dessas informações específicas da estrutura, levantam-se dados históricos, a partir da conversa com os proprietários. $O$ ambiente no qual a estrutura se insere recebe igual descrição. Os registros fotográficos são anexados às referidas fichas e constam desse levantamento patrimonial do Vale do Taquari/RS. Apesar de aparentemente simples, o registro dessas estruturas, bem como de seus anexos e entornos, é ponto de partida para elucubrações mais elaboradas a respeito da ocupação, especialmente do período histórico da região.

Nesse sentido, os objetos encontrados nesses lugares adquirem status de Cultura Material, permitindo a partir da decifração de seus signos, a leitura do cotidiano tanto dos colonizadores portugueses e seus escravos quanto dos imigrantes italianos e alemães do século XIX. Apesar da definição ampla de patrimônio utilizada para embasar este trabalho, o levantamento em questão é delimitado pela possibilidade de abordagem pelos métodos correntes em Arqueologia. Dessa forma, a abordagem patrimonial torna-se viável desde sítios arqueológicos pré-históricos a abordagens mais específicas em Arqueologia Histórica com foco no período, que convencionalmente, chamamos período histórico. Embora pareça uma abordagem reduzida, patrimonialmente falando, levantar-se-ão dados desde casas de moradia, comércio, salões de bailes, cemitérios, tafonas, moinhos e demais estruturas que remetam à memória das comunidades locais.

A necessidade de recuperar as informações arqueológicas e históricas, sobretudo referentes aos tempos mais remotos da atividade humana na região, acentua o papel desta instituição como polo gerador de conhecimento, revertendo os resultados 
ARQUEOLOGIA HISTÓRICA E A PROBLEMÁTICA DO PATRIMÔNIO...

desta pesquisa em benefícios coletivos. Sendo que a "exploração e valorização dos territórios nacionais implicam também num relacionamento particular entre a Arqueologia, a sociedade e os grupos no poder. Trata-se, em geral, da incorporação de monumentos e objetos numa prática de valorização e transformação econômica da paisagem." (Funari, 1988).

\section{Reflexões conclusivas: impulsos para a sequência do trabalho}

As verdades não perenes da ciência contemporânea impulsionam o fazer do pesquisador que sustenta este epíteto. Quando o objeto pesquisado deriva da subjetividade humana, os pilares sustentadores das verdades criados na modernidade, sob a regência do pensamento positivista, não se sustentam. Os conceitos "movediços" das ciências humanas (classificação já contestada, uma vez que alguns teóricos defendem que todas as ciências são humanas) oriundos do rompimento, cada vez mais frequente, da fragmentação científica são responsáveis diretos por esse alargamento de horizontes. Dessa forma, a abordagem holística do homem passa a ser o grande impulso para o fazer científico.

Em se tratando de Vale do Taquari, o estudo arqueológico do Patrimônio Cultural é de fundamental importância para o preenchimento de uma grande lacuna no que se refere ao fazer do homem, tanto no período concebido como pré-histórico quanto no histórico. Essa abordagem embasada em métodos capazes de romper com pré-conceitos estabelecidos e cultivados pela arrogância intelectual deve ter presente a pluralidade de fontes e promover o diálogo entre ambas, sem hierarquizá-las conforme se propõe fazer a Arqueologia Histórica.

A concretude da Cultura Material abriga, num aparente paradoxo, uma pluralidade de interpretações capazes de referenciar vários momentos do cotidiano humano.

A "evolução" do pensamento, mesmo que a partir de interpretações particulares, está expressa tanto nos objetos quanto nas edificações dos diferentes municípios da região. 
Ainda que conscientes do êxito alcançado até aqui, não se pode ignorar a indelegável tarefa que a sociedade atribuí àqueles que se propõem a mediar a relação embaraçosa da imanente heterogeneidade humana.

Alguns passos estão sendo dados simultaneamente nesse sentido. Primeiramente, a partir do caminho já percorrido, a consciência do valor cultural do patrimônio tende a solidificar-se aos poucos. Além disso, permeia-se através da divulgação das pesquisas realizadas no meio acadêmico, e de projetos educacionais e turísticos promovidos por entidades privadas ou públicas, a disseminação de conhecimento referente ao patrimônio junto à sociedade. Dessa forma, dar-se-á um melhor tratamento a questões como a preservação, e principalmente, à construção de "identidades" individuais e coletivas.

\section{REFERÊNCIAS BIBLIOGRÁFICAS}

AHLERT, Lucildo e GEDOZ, Sirlei Teresinha. Povoamento de desenvolvimento econômico na região do vale do Taquari, Rio Grande do Sul 1822 a 1930. Revista Estudo \& Debate. Ano 8, n.1. Lajeado: UNIVATES, 2001.

BARRETO, Margarida. Turismo e legado cultural: as possibilidades do planejamento. Campinas: Papirus, 2000.

CHOAY, Françoise. A alegoria do patrimônio. São Paulo: UNESP, 2001. EIFLER, Ellen Walquíria. Bom Retiro do Sul: sua história... sua vida. Porto Alegre: Editora FEPLAM, 1992.

FONSECA, Maria Cecília Londres. O Patrimônio em processo: trajetória da política federal de preservação no Brasil. Rio de Janeiro: UFRJ; MinC, IPHAN, 2005.

FUNARI, Pedro Paulo Abreu. Arqueologia. São Paulo: Editora Ática, 1988.

FUNARI, Pedro Paulo e FOGOLARI, Everson Paulo. Estudos de Arqueologia Histórica. Erechim: sem editora, 2005

HORTA, Maria de L. P.; GRUNBERG, Evelina; MONTEIRO, Adriane Q. Guia básico de educação patrimonial. Brasília: IPHAN, Museu Imperial, 1999.

ORSER JR., Charles E. Introdução à arqueologia histórica. Belo Horizonte: Oficina de Livros, 1992. 
OOSTERBEEK, Luiz. Arqueologia, patrimônio e gestão do território. Erechim: Habilis, 2007.

RODRIGUES, Marly. De quem é o patrimônio? Um olhar sobre a prática preservacionista em São Paulo. Revista do Patrimônio Histórico e Artístico Nacional, n.24: 195-203, Rio de Janeiro, 1996.

SILVA, Thiago Pereira da. Reflexões sobre os primórdios do turismo em Ouro Preto. 2006. http://www.ouropreto.com.br

VARELA, Daniela. Turismo e Cultura - referências da identidade humana. 2006, http://www.ouropreto.com.br

MACHADO, Neli T. Galarce; LOPES, Sérgio Nunes; Diego Antônio GHENO. Historical Archaeology and the Heritage Problem: discussions about preservation, tourism and heritage education in the Vale do Taquari - Rio Grande do Sul. História, v.28, n.1, p.575-588, 2009.

\begin{abstract}
The research in Historical Archaeology in the Vale do Taquari is recent and seeks a better understanding of the quotidian life of human groups derived from Portuguese colonization in the eighteenth century and from European immigration in the nineteenth century. Among the origins of these groups we can cite basically the Azoreans, Germans and Italians. Furthermore, Historical Archaeology is a fundamental field of knowledge to archaeological research and its dissemination. Historical Archaeology appeals to Historicalcultural Heritage preservation and from the acquisition of concrete information opens the possibility of producing knowledge that is able to correct historical distortions. These are some approaches presented in the article. Interconnection with the communicative capacity of education and tourism are some means considered potential toward the preservation of the Heritage of the Vale do Taquari. However with respect to Heritage Education some concrete data are shared, as research accomplished in this context has obtained satisfactory results.
\end{abstract}

Keywords: Historical Archaeology, Cultural Heritage, Vale do Taquari

Artigo recebido em 03/2009. Aprovado em 05/2009

HISTÓRIA, São Paulo, 28 (1): 2009 